\title{
Vulvar leukoplakia: therapeutic options
}

\author{
Angel Yordanov ${ }^{1}$, Latchezar Tantchev ${ }^{2}$, Stoyan Kostov³ ${ }^{3}$ Stanislav Slavchev ${ }^{3}$, Strahil Strashilov ${ }^{4}$ \\ Polina Vasileva ${ }^{5}$
}

${ }^{1}$ Department of Gynaecological Oncology, Medical University of Pleven, Bulgaria

${ }^{2}$ Obstetrics and Gynaecology Clinic, Acibadem City Clinic Hospital “Tokuda”, Sofia, Bulgaria

${ }^{3}$ Department of Gynecology, Medical University of Varna, Bulgaria

${ }^{4}$ Department of Plastic Restorative, Reconstructive and Aesthetic Surgery, Medical University of Pleven, Bulgaria

${ }^{5}$ Department of Obstetrics and Gynaecology, Medical University of Pleven, Pleven, Bulgaria

\begin{abstract}
Vulvar leukoplakia is not a histological diagnosis and involves several diseases. Most commonly, these are vulvar lichen sclerosus and squamous cell hyperplasia of the vulva. These two conditions have similar aetiology, clinical presentation and treatment but different histopathological changes. They both lead to significant impairment of quality of life, risk of malignancy, as well as recurrence after treatment.

Treatment of these conditions includes topical corticosteroids as a first-line therapy, but they have their side effects and not all patients are receptive to this therapy. This requires the use of alternative therapeutic options such as topical calcineurin inhibitors, topical and systemic retinoids, other steroid creams, various destructive techniques and, as a last resort, surgical removal of affected tissues. Surgical treatment should be avoided, despite the malignant potential, because of recurrence risk in both diseases

New therapeutic approaches are coming into effect in gynaecological practice due to potential risks of the above-mentioned methods. Platelet-rich plasma therapy, ablative and non-ablative laser treatment, and new topical medicines, are some of the new options applied to improve the efficacy of treatment avoiding the side effects of conventional medications. A number of them are still in their initial phase of application and time will tell their effectiveness.
\end{abstract}

Key words: vulvar leukoplakia, vulvar lichen sclerosus, squamous cell hyperplasia of the vulva, treatment.

\section{Introduction}

The term vulvar leukoplakia is not a histological but a descriptive diagnosis meaning "white spot". It is used for non-inflammatory diseases characterized by pathological modification of external genitalia multilayered flat epithelium that is accompanied by skin and mucosa cornification [1]. It combines various atrophic and hypertrophic diseases of the vulva classified in the past as vulvar dystrophies [2]. This group includes lichen sclerosus (LS), squamous cell hyperplasia, condyloma acuminata, psoriasis, lichen planus, mixed LS and atrophicus. White colouration is caused by excessive keratin, at times deep pigmentation, and relative avascularity [3] Two non-neoplastic epithelial disorders of the vulva vulvar LS (VLS) and squamous cell hyperplasia of the vulva (SCHV) - are generally referred to as vulvar leukoplakia. They have different anatomical and pathological features, but similar clinical manifestations. The frequency is 1 in 300 to 1,000 [4]. Treatment involves different approaches such as topical medications, platelet- rich plasma (PRP) therapy, various destructive techniques, e.g. ablative and non-ablative laser treatments, alcohol-mediated denervation and, in the last instance, surgical removal of the affected tissues.

\section{Aetiology}

The two major diseases leading to white skin coloration in the external genitalia are VLS and SCHV. These are chronic conditions and their occurrence is determined by many factors such as immunity, sexual hormones, injuries, environment, enzymes, free radicals, and apoptosis. It is assumed that VLS and SCHV are genetic immune diseases [5].

VLS is the most common chronic lesion of the vulva and mainly affects the anogenital area [4, 5], but may have extragenital location as well. In $20 \%$ of patients with anogenital involvement extragenital involvement is found too [6-9]; in 6-15\% of LS cases disease manifestations have extragenital locations only [8, 9]. The classical 
histological findings of LS are a thinned epidermis and/ or the loss of rete ridges, hyperkeratosis, oedema and/or hyalinization, as well as chronic band-like inflammatory cell infiltrate of the dermis [10]. However, there are many variations to these classical histological characteristics leading to a myriad of lesions that may be classified as LS [11]. Macroscopically, the vulva is shiny and dry, with no creases. Lesions are often symmetrical. The disease is more common in postmenopausal women, but there is a peak in its development in pre-pubertal girls as well $[7,9,12]$. It affects mostly women aged 50-59 [4]. It is assumed to be of autoimmune genesis with a genetic predisposition [5, 13]. Autoimmune diseases are diagnosed in $21 \%$ of cases of VLS, and in $22 \%$ of cases family history of the disease [2] affects sisters, mothers and daughters, and twin sisters including both homozygotic and heterozygotic twins [5].

The aetiology of SCHV is not well known. It is supposed there is a role of chronic irritation of the skin. Irritants might include perfumed soaps, fabric conditioners and detergents used in the laundry of underwear or even excessive washing [14]. It is thought that SCHV is an autoimmune condition and it has been associated with other autoimmune diseases such as malignant anaemia, thyroid diseases, diabetes mellitus, systemic lupus erythematosus, primary biliary cirrhosis, and bullous pemphigoid [2].

There is thinning of the affected skin in VLS, while the opposite is observed in SCHV - an abnormal growth of the skin of the vulva. The histological features are as follows: widening of the rete ridges and irregular thickening of the Malpighian layer of rete ridges (acanthosis); hyperkeratosis and chronic inflammation in the dermis; possibly increased mitotic figures in basal and prickle cell layers but no atypia; possible parakeratosis.

This condition is characterized by a pink-red vulva with overlying grey-white keratin and involved labium majus, nympholabial furrow, preputium clitoridis, and commissura labiorum posterior. In the early stage of the disease, the skin might appear dark red or pink, while hyperkeratotic skin might appear white.

The disease is predominant in postmenopausal women but can be observed in any lifetime period [15-17]. The average age of its occurrence is between 42 and 53 years of age according to research literature $[18,19]$.

\section{Clinical manifestation}

The clinical picture in both conditions is similar, and its main manifestation is itching in the vulva which is more expressed in SCHV than in VLS [5]. Other less common symptoms are dyspareunia and dysuria.

Rarely VLS can be asymptomatic. Usual symptoms are pruritus, burning, or stinging of the vulva, white or grey patches of thickening or thinning on the vulvar skin. At the early stage of VLS the symptoms are swell- ing and redness of the skin and the lesion can further progress to white, thin, dry, and chapped skin and mucosa with a loss of elasticity as the disease advances. There can be atrophy or even a reduction in the labiorum minus [5].

VLS and SCHV may cause significant vulvar changes affecting quality of life. Anatomical changes that are caused by both conditions, especially from VLS, may lead to sexual dysfunction [13]. Both conditions have an opportunity to relapse after treatment, and this is related to the method of treatment and patients' age $[20,21]$.

They have a malignant potential: 3 to $6 \%$ for VLS and 2 to $4 \%$ for SCHV [5]. It has been established that VLS patients can develop vulvar squamous cell carcinoma for several years - from 3.3 to 8.8 years [22, 23]. About $80 \%$ of the cases of invasive squamous cell carcinoma (SCC) of the vulva in elderly patients are associated with untreated, long-term VLS conditions [4].

Because of the malignant potential of these diseases, many clinicians advocate that active management of VLS and SCHV can reduce the risk of malignant transformation [22].

\section{Diagnosis}

The diagnosis of both diseases is clinical, which is sufficient in routine clinical practice. It is very easy to diagnosticate then when the clinical presentation is typical, especially for LVS [24-26]. In some cases such as atypical features, uncertainty of diagnosis, concern for malignancy, or in failed response to treatment, biopsy is mandatory. The gold standard to differentiate these conditions is histological - biopsy [22, 27]. Because biopsy is the only way to exclude SCC of the vulva and vulvar intraepithelial neoplasia, it is necessary in our opinion.

\section{Treatment}

Both diseases have similar treatment, but different therapeutic options are available as well. The main goal of therapy is to control genital itching, which is a major problem for the patient. Management of pruritus vulvae can be divided into four stages: (1) identification of underlying disease; (2) restoration of the skin barrier function; (3) reduction of any inflammatory complication; and (4) elimination of the itch-scratch cycle by psychological methods [28]. Asymptomatic VLS cases should be treated too.

The first course of action in both conditions is to minimize irritants, soap substitution, avoidance of urinary contact, moisturization with emollients, and treatment of co-infections [29].

Topical corticosteroids are the gold standard for treatment of these patients. Ultra-potent corticosteroid 
ointments or creams are used as there are not enough randomized controlled trials providing records on how often, how long, and in what potency the corticosteroids are to be applied [16]. In the last few years some trials were published about what kind of corticosteroids has to be used for LVS treatment, the duration of the treatment period and the safety of treatment. They all reported no differences in results depending of different types of steroids or different ways of application and they did not report any serious adverse events [30-32]. It should be noted that long-term use of steroid creams or ointments can cause reddening or thinning of the skin, stretch marks and genital yeast infections. They relieve the symptoms in nearly all patients; in about $70 \%$ of the cases, symptoms disappear completely, and in $20 \%$ complete recovery of the skin is observed [29]. The British Association of Dermatologists guidelines advocate their use and propose a detailed dosing regimen [27]. The recommendations for newly diagnosed cases are: application of clobetasol propionate $0.05 \%$ ointment once daily at night time for the duration of 4 weeks, followed by application on alternate nights for 4 weeks, and then twice weekly for a further 4 weeks. In recurrence of symptoms with reduced frequency, the patient should apply treatment until symptoms resolve. An ointment formulation is usually better tolerated than a cream base [29]. Other corticosteroids may be used in doses twice daily for several weeks and then twice weekly. Overuse of superpotent topical corticosteroids may induce atrophy, telangiectasia, and striae as early as 2-3 weeks following daily application. Treatment of SCHV is similar and corticosteroid creams are applied [20].

If VLS treatment fails, there are some alternative, less popular options such as the use of topical calcineurin inhibitors (TCls). Pimecrolimus and tacrolimus are used. These drugs have a pronounced anti-inflammatory effect, an immunomodulatory effect and a weakly pronounced immunosuppressive effect; adverse effects of these agents have not been described. Some authors believe that they may increase the risk of VLS progression to malignancy [34, 35]. The described dose of tacrolimus ointment is twice daily until symptoms disappear [36, 25], and the course of treatment should not be too long. It should only be used in patients refractory to corticosteroid treatment.

The use of topical testosterone in the treatment of VLS has already stopped due to worse results compared to those of ultrapotent topical corticosteroids and its side effects: systemic absorption and virilizing effects in female patients [37-41].

Local oestrogens are another treatment option for SCHV. However, they have serious adverse effects such as increasing the risk of endometrial hyperplasia and overstimulation [42].
Another option for vulvar leukoplakia treatment is the topical and systemic retinoids. They are not widely used because of adverse effects such as skin irritation and low tolerance to sunlight exposure for the topical forms; and mucocutaneous side effects, cheilitis, dryness of the oral mucosa, epistaxis, xerophthalmia, xerosis and fissuring of fingertips, hair loss, nail fragility, periungual granuloma, and paronychia manifested in patients treated with systemic retinoids [43].

Further treatment options for VLS are UV-A1 phototherapy, photodynamic therapy, oral acitretin, and topical progesterone/testosterone, but they should only be used as $3^{\text {rd }}$-line therapy $[44,45]$. These methods have been described in extremely few patients and cannot be routinely applied.

Increasingly, reports of successful PRP treatment of VLS [46] have appeared in the literature. However promising it may be, this is not a standard treatment.

With the advent of medical lasers, reports of their use in the treatment of VLS have appeared frequently lately. They are less commonly used in SCHV treatment. Ablative lasers (carbon dioxide laser) [47-50], and non-ablative neodymium: yttrium aluminium garnet (Nd: YAG) lasers [51] are used in different operating modes. Both types of lasers have positive results, but non-ablative ones, unlike ablative lasers, have no side effects such as pain, discomfort, scars, infections, pigmentation or bleeding.

Vaporization, ultrasonic surgical aspiration, loop excision, simple lesion excision, and cryotherapy are some further therapeutic options to broaden the spectrum of SCHV treatment options.

Itching appears to be patients' main discomfort, and the use of some other types of non-steroid agents is another option. There have been reports of isolated cases of VLS and SCHV successfully treated with Theresienol herbal oil [48]. The treatment course with Theresienol herbal oil lasts for several months, but with no side effects as described with corticosteroid treatment [52]. This product is for topical administration and has the following mechanism of action: it hydrates the tissues; reduces bacterial invasion and inflammation; stimulates fibroblast and endothelial cell migration and proliferation; and stimulates epithelialization. Thereby, it has analgesic, antiseptic and moisturizing effects and reduces skin itching.

Surgical treatment of both diseases should be avoided because of recurrence risk and should only be used in certain cases, such as patients with malignancy, or to correct irreversible scarring, adhesions and micturition difficulties or sexual dysfunction caused by the subsequent anatomical changes [29]. If all conservative treatment measures have failed, surgical treatment is indicated. However, vulvectomy and skinning vulvectomy should be avoided because of recurrence rates and disfigurement. 


\section{Conclusions}

The term leukoplakia should not be used in medical practice and should be replaced by the name of the condition that leads to coloration of the vulva. Most commonly there are two conditions that lead to white discoloration of the external genitalia: vulvar LS and SCHV. Both diseases have similar clinical features and malignant potential and therefore should be treated. Histological diagnosis is not necessary in clinical practice (but this is the only way to exclude SCC or VIN) since topical corticosteroids are the first-line therapy for these conditions. Histological verification is important in cases of corticosteroid-resistant patients, as they are subject to different therapeutic methods. Increasing numbers of new and alternative treatments such as PRP, Nd: YAG laser, Theresienol, and avoiding the side effects of conventional treatment, have been reported lately in research literature. Surgical treatment should be avoided, despite the malignant potential, because of recurrence risk in both diseases.

\section{Disclosure}

The authors report no conflict of interest.

\section{References}

1. Liu GL, Cao FL, Zhao MY, et al. Associations between HLA-A \B\DRB1 polymorphisms and risks of vulvar lichen sclerosus or squamous cell hyperplasia of the vulva. Genet Mol Res 2015; 14: 15962-15971.

2. Viana F de O, Cavaleiro LH, Unger DA, et al. Acral lichen sclerosus et atrophicus - case report. An Bras Dermatol 2011; 86: 82-84.

3. Halonen P, Jakobsson M, Heikinheimo O, et al. Lichen sclerosus and risk of cancer. Int J Cancer 2017; 140: 1998-2002.

4. Powell JJ, Wojnarowska F. Lichen sclerosus. Lancet 1999; 353: $1777-$ 1783.

5. van de Nieuwenhof HP, van der Avoort I, de Hullu JA. Review of squamous premalignant vulvar lesions. Crit Rev Oncol Hematol 2008; 68: 131-156.

6. Meffert JJ, Davis BM, Grimwood RE. Lichen sclerosus. J Am Acad Dermatol 1995; 32: 393-416.

7. Wallace HJ. Lichen sclerosus et atrophicus. Trans St Johns Hosp Dermatol Soc 1971; 57: 9-30.

8. Wilkinson E. Premalignant and malignant tumors of the vulva. Blaustein's Pathology of the Female Genital Tract, $5^{\text {th }}$ ed. 2002: 99-150.

9. van de Nieuwenhof HP, Bulten J, Hollema $\mathrm{H}$, et al. Differentiated vulvar intraepithelial neoplasia is often found in lesions, previously diagnosed as lichen sclerosus, which have progressed to vulvar squamous cell carcinoma. Mod Pathol 2011; 24: 297-305.

10. Powell J, Wojnarowska F. Childhood vulvar lichen sclerosus: an increasingly common problem. J Am Acad Dermatol 2001; 44: 803-806.

11. Berth-Jones J, Graham-Brown RAC, Burns DA. Lichen sclerosus. Arch Dis Child 1989; 64: 1204-1206.

12. Chan MP, Zimarowski MJ. Vulvar dermatoses: a histopathologic review and classification of 183 cases. J Cutan Pathol 2015; 42: 510-518.

13. Haefner HK, Aldrich NZ, Dalton VK, et al. The impact of vulvar lichen sclerosus on sexual dysfunction. J Womens Health (Larchmt) 2014; 23: 765-770.

14. http://www.swbh.nhs.uk/wp-content/uploads/2012/07/Squamouscell-hyperplasia-and-lichen-planus-ML4618.pdf

15. Bleeker MC, Visser PJ, Overbeek LI, et al. Lichen sclerosus: incidence and risk of vulvar squamous cell carcinoma. Cancer Epidemiol Biomarkers Prev 2016; 25: 1224-1230.
16. Fistarol SK, Itin PH. Diagnosis and treatment of lichen sclerosus: an update. Am J Clin Dermatol 2013; 14: 27-47.

17. Rioux JE, Devlin C, Gelfand MM, et al. 17beta-estradiol vaginal tablet versus conjugated equine estrogen vaginal cream to relieve menopausal atrophic vaginitis. Menopause 2000; 7: 156-161.

18. http://www.uptodate.com/contents/vulvar-lichen sclerosus? source= search_result\&search=vulvar+lichen+sclerosus\&selectedTitle $=1 \sim 13$

19. Horowitz IR. Neoplasms of the vulva. In: Conn's Current Therapy, $51^{\text {st }}$ ed., Rakel RE (ed.). W B Saunders Co 1999.

20. Ayhan A, Guvendag Guven ES, Guven S, et al. Medical treatment of vulvar squamous cell hyperplasia. Int J Gynaecol Obstet 2006; 95: 278-283.

21. Renaud-Vilmer C, Cavelier-Balloy B, Porcher R, Dubertret L. Vulvar lichen sclerosus: effect of long-term topical application of a potent steroid on the course of the disease. Arch Dermatol 2004; 140: 709-712.

22. Tsikouras P, Anthoulaki X, Deftereou T, et al. Depigmentation's Disorders of the Vulva, Clinical Management. In: Depigmentation, Kim T-H (ed.). IntechOpen 2019.

23. DiSaia P. Noninvasive vulvar lesions. An illustrated guide to diagnosis and treatment. Dystrophies, vulvodynia and other noncancerous lesions. OBG Manag 2006; 18: 62-77.

24. Lee A, Bradford J, Fischer G. Long-term management of adult vulvar lichen sclerosus: a prospective cohort study of 507 women. JAMA Dermatol 2015; 151: 1061-1067.

25. Neill SM, Lewis FM, Tatnall FM, et al. British Association of Dermatologists' guidelines for the management of lichen sclerosus 2010. Br J Dermatol 2010; 163: 672-682.

26. Lewis FM, Tatnall FM, Velangi SS, et al. British association of dermatologists guidelines for the management of lichen sclerosus 2018. Br J Dermatol 2018; 178: 823-824.

27. Sharova A, Farrakhova D, Slovokhodov E, et al. Evaluation of vulvar leukoplakia photodynamic therapy efficiency by fluorescent diagnostics method with local «Alasens ${ }^{\circledR}$ » photosensitizer application. Photodiagnosis Photodyn Ther 2019; 27: 105-110.

28. Soper JT, Creasman WT. Vulvar dystrophies. Clin Obstet 1986; 29: 431439

29. Kaufman RH, Gardner HL, Brown Jr D, Beyth Y. Vulvar dystrophies: an evaluation. Am J Obstet Gynecol 1974; 120: 363-367.

30. Chi CC, Kirtschig G, Baldo M, et al. Topical interventions for genital lichen sclerosus. Cochrane Database Syst Rev 2011; 7: CD008240.

31. Borghi A, Corazza M, Minghetti S, et al. Continuous vs. tapering application of the potent topical corticosteroid mometasone furoate in the treatment of vulvar lichen sclerosus: results of a randomized trial. Br J Dermatol 2015; 173: 1381-1386.

32. Corazza M, Borghi A, Minghetti S, et al. Clobetasol propionate vs. mometasone furoate in 1-year proactive maintenance therapy of vulvar lichen sclerosus: results from a comparative trial. J Eur Acad Dermatol Venereol 2016; 30: 956-961.

33. Barbero $M$, Micheletti L, Borgno $G$, et al. Vulvar dystrophies in young and premenopausal women. J Reprod Med 1988; 33: 555-558.

34. Clark TJ, Etherington IJ, Luesley DM. Response of vulvar lichen sclerosus and squamous cell hyperplasia to graduated topical steroids. J Reprod Med 1999; 44: 958-962.

35. Matsumoto $Y$, Yamamoto T, Isobe T, et al. Successful treatment of vulvar lichen sclerosus in a child with low-concentration topical tacrolimus ointment. J Dermatol 2007; 34: 114-116.

36. Kim GW, Park HJ, Kim HS, et al. Topical tacrolimus ointment for the treatment of lichen sclerosus, comparing genital and extragenital involvement. J Dermatol 2012; 39: 145-150.

37. Bunker CB. Male genital lichen sclerosus and tacrolimus. Br J Dermatol 2007; 157: 1079-1080

38. Bunker CB. Comments on the British Association of Dermatologists guidelines for the management of lichen sclerosus. Br J Dermatol 2011; 164: 894-895.

39. Cattaneo A, De Marco A, Sonni L, et al. Clobetasol vs. Testosterone in the treatment of lichen sclerosus of the vulvar region. Minerva Ginecol 1992; 44: 567-571.

40. Ayhan A, Guven ES, Guven S, et al. Testosterone versus clobetasol for maintenance of vulvar lichen sclerosus associated with variable degrees of squamous cell hyperplasia. Acta Obstet Gynecol Scand 2007; 86: 715-719. 
41. Bornstein J, Heifetz S, Kellner Y, et al. Clobetasol dipropionate 0.05\% versus testosterone propionate $2 \%$ topical application for severe vulvar lichen sclerosus. Am J Obstet Gynecol 1998; 178: 80-84.

42. Mangold R, Heilmann V, Rossmanith WG. Iatrogenic androgenization. Zentralbl Gynakol 1998; 120: 515-517.

43. Joura EA, Zeisler H, Bancher-Todesca D, et al. Short-term effects of topical testosterone in vulvar lichen sclerosus. Obstet Gynecol 1997; 89: 297-299.

44. Khalil S, Bardawil T, Stephan C, et al. Retinoids: a journey from the molecular structures and mechanisms of action to clinical uses in dermatology and adverse effects. J Dermatolog Treat 2017; 28: 684-696.

45. Ayhan A, Guvendag Guven ES, Guven S, et al. Medical treatment of vulvar squamous cell hyperplasia. Int J Gynaecol Obstet 2006; 95: 278-283.

46. Kim SH, Park ES, Kim TH. Rejuvenation Using Platelet-rich Plasma and Lipofilling for Vaginal Atrophy and Lichen Sclerosus. J Menopausal Med 2017; 23: 63-68.

47. Lee A, Lim A, Fischer G. Fractional carbon dioxide laser in recalcitrant vulval lichen sclerosus. Australas J Dermatol 2016; 57: 39-43.

48. Origoni M. Fractional carbon dioxide laser in recalcitrant vulvar lichen sclerosus [letter]. Australas J Dermatol 2017; 58: e157-158.

49. Stuart GC, Nation JG, Malliah VS, et al. Laser therapy of vulvar lichen sclerosus et atrophicus. Can J Surg 1991; 34: 469-470.

50. Volz J, Blanke M, Melchert F. Treatment of therapy refractory squamous epithelial hyperplasia of the vulva by $\mathrm{CO} 2$ laser vaporization. Geburtshilfe Frauenheilkd 1994; 54: 406-408. [Article in German]

51. Bizjak Ogrinc U, Senčar S, Luzar B, Lukanović A. Efficacy of Non-ablative Laser Therapy for Lichen Sclerosus: A Randomized Controlled Trial. J Obstet Gynaecol Can 2019; 41: 1717-1725.

52. Yordanov AD, Vasileva PP, Strashilov SA, Konsoulova A. Treatment of vulvar leukoplakia with Theresienol - a new opportunity. Arch Balk Med Union 2019; 53: 753-758.w 